\title{
Determination of Trace Lithium in Human Urine by Electrothermal Atomic Absorption Spectrometry Using Nitric Acid as a Chemical Modifier to Eliminate the Interference of Chloride
}

\author{
Jianxing ZHaO, ${ }^{\dagger}$ Pingjin GaO, Shengnan Wu, and Dingliang ZHU \\ Shanghai Key Laboratory of Vascular Biology at Ruijin Hospital and Shanghai Institute of Hypertension, \\ Shanghai Jiao Tong University School of Medicine, Shanghai 200025, China
}

\begin{abstract}
Electrothermal atomic absorption spectrometry (ETAAS) is considered the most common and advanced technique to determine trace lithium in biological fluids. However, chloride existing in samples has been reported to create serious interferences. Nitric acid was verified as a chemical modifier to eliminate the interference of chloride in determining trace lithium in urine samples and the possible mechanism was also elucidated. The influence of chloride was completely eliminated by using $0.5 \%(\mathrm{v} / \mathrm{v}) \mathrm{HNO}_{3}$ as a chemical modifier. Confidence interval analysis on the difference for the slopes of linear regression curves indicated no significant difference between the slopes of aqueous and of urine-matched standard curves with and without $30 \mathrm{mmol} / \mathrm{L} \mathrm{NaCl}$ in the presence of $0.5 \%(\mathrm{v} / \mathrm{v}) \mathrm{HNO}_{3}(P=0.146)$. Thus the direct standardization with an aqueous calibration curve could be used instead of the standard-addition method. We conclude that the developed method is accurate and easily applicable for both routine use and research investigations.
\end{abstract}

(Received August 4, 2008; Accepted September 22, 2008; Published May 10, 2009)

\section{Introduction}

Because of the biological and biochemical importance, the concentration of physiological levels of trace lithium in body fluids is used as a biological indicator of human health and disease; its determination has thus received great attention from biological and medical researchers. Determination of trace lithium in biological fluids has been carried out by using some sensitive methods, such as atomic emission spectrometry (AES), ${ }^{1-3}$ inductively coupled plasma atomic emission spectrometry (ICP-AES), ${ }^{4-6}$ inductively coupled plasma mass spectrometry (ICP-MS), ${ }^{7-9}$ isotope dilution mass spectrometry $(\text { IDMS })^{10,11}$ and electrothermal atomic absorption spectrometry (ETAAS). ${ }^{9}{ }^{12-23}$ Among these techniques, ETAAS has been shown to be very attractive, since it requires low sample volume and provides adequate sensitivity, low detection limits and the possibility of measurements after just a simple dilution step (no need for sample mineralization). However, chloride has been reported to create serious interferences in ETAAS analyses of lithium. ${ }^{18}$ Specific methods were used in order to cope with such interference. Some authors recommended the use of chemical modifiers such as ammonium nitrate ${ }^{19,21}$ or phosphate. ${ }^{23}$ Others reported using tantalum-coated tubes ${ }^{18}$ or coated tubes in combination with chemical modifiers (tantalum carbide-coated graphite tubes-ammonium nitrate, ${ }^{22}$ tungstatecoated graphite tubes-ammonium sulfate), ${ }^{14}$ or tubes lined with tantalum foil. ${ }^{17,20}$ Magnin et al..$^{15}$ reported that, even if one uses pyrolitically-coated graphite tubes in combination with ammonium nitrate, the method still could not completely abolish the interferences caused by the matrix, notably in urine samples.

† To whom correspondence should be addressed.

E-mail: jzhao021@yahoo.com
So they used solid-phase extraction on strongly acidic cation exchange cartridges to separate the interferents from the urine matrix. The method of extraction to separate lithium from urine matrix was also used by Steinhäuslin et $a{ }^{19}{ }^{19}$ It was quite timeconsuming and not convenient.

In the present study, the effectiveness of nitric acid as a chemical modifier to eliminate the interference of chloride has been investigated for the determination of trace lithium in urine, which contains a large amount of chloride.

\section{Experimental}

\section{Reagents and chemicals}

All chemicals employed were from Sinopharm Chemical Reagent Co., Ltd. They were analytical reagent grade unless otherwise specified. All solutions were prepared with high purity distilled water. A stock standard lithium solution (100 $\mathrm{mmol} / \mathrm{L}$ ) was made by weighing $0.369 \mathrm{~g}$ of extra pure $(99.99 \%)$ $\mathrm{Li}_{2} \mathrm{CO}_{3}$ into a $100-\mathrm{ml}$ volumetric flask; the salt was dissolved with a few drops of $\mathrm{HCl}$ and the contents were made up to volume with distilled water. The working standard solutions were prepared before use by diluting the stock standard solution with $0.5 \%(\mathrm{v} / \mathrm{v}) \mathrm{HNO}_{3}$. Concentrated nitric acid (guaranteed reagent) was diluted with distilled water to $0.5 \%(\mathrm{v} / \mathrm{v})$ in the final concentration as a chemical modifier. Then, $1 \mathrm{~mol} / \mathrm{L}$ of spectrum pure grade $\mathrm{NaCl}$ was prepared for the interferential test and final concentrations were used for the consideration of the concentrations of chlorine existing in urine after 10 times dilution. High purity distilled water with an absorbance about 0.0050 (the same as for an air injection) was obtained through a distilled water system made of quartz. 
Table 1 Time-temperature program for the determination of lithium in urine

\begin{tabular}{ccrcc}
\hline Step & $\begin{array}{c}\text { Furnace } \\
\text { temperature } /{ }^{\circ} \mathrm{C}\end{array}$ & $\begin{array}{c}\text { Ramp/ } \\
{ }^{\circ} \mathrm{C} \mathrm{s}^{-1}\end{array}$ & Hold/s & $\begin{array}{c}\text { Argon flow rate/ } \\
\mathrm{ml} \mathrm{min}^{-1}\end{array}$ \\
\hline 1 & 100 & 10 & 30 & 200 \\
2 & 150 & 100 & 10 & 200 \\
3 & 800 & 150 & 20 & 200 \\
4 & 2700 & 0 & 3 & 0 \\
5 & 2800 & 0 & 3 & 200 \\
\hline
\end{tabular}

\section{Apparatus}

All measurements were carried out using a Thermo S2 atomic absorption spectrometer (England) equipped with a GFS 97 graphite furnace (England) and a GFS 97 furnace autosampler (England). The light source was a lithium hollow cathode lamp (Thermo, UK) operating at $7 \mathrm{~mA}$ current at the $670.8 \mathrm{~nm}$ resonance line. The bandwidth of the spectrometer used was 0.2 $\mathrm{nm}$ (half height). Extended lifetime cuvettes (Thermo Elemental, part No. 9423393 95041, Germany) were used for all of the experiments. The furnace temperature program used is given in Table 1. Argon was used as purge gas. All pipettes used were Finnpipettes (Thermo Electron) equipped with disposable polypropylene pipette tips.

\section{Analytical procedure}

Urine samples were diluted $1: 10$ by $0.55 \% \mathrm{HNO}_{3}(\mathrm{v} / \mathrm{v})$ in the special cups for autosampler. Five microliters of this solution were injected into the graphite tube directly. The atomic absorption was measured under the ETAAS operating conditions as given in the description of the apparatus and in Table 1. Two drying steps with different temperatures were used in order to avoid possible sputtering. The concentrations of lithium in urine samples were obtained by a general standard curve method. Absorbances were measured using peak height for calibration because of the higher sensitivity.

\section{Statistical analysis}

Data were analyzed as mean \pm standard deviation (SD) and evaluated statistically by the student's $t$-test. GraghPad Prism software was used to test whether slopes of linear regression curves were significantly different. Significance was determined as $P<0.05$.

\section{Results and Discussion}

\section{Pyrolysis and atomization temperature optimization}

To establish an optimal temperature program for the determination of lithium in urine by ETAAS, we used $0.5 \mu \mathrm{mol} / \mathrm{L}$ $\mathrm{Li}$ and urine (diluted 1:10) as the specimens for observing the pyrolysis and atomization temperature for the graphite furnace heating program. As $0.5 \% \mathrm{HNO}_{3}$ is the most common medium used in atomic absorption analysis, we also observed $\mathrm{Li}$ pyrolysis and atomization temperature curves in this medium as well as in $\mathrm{H}_{2} \mathrm{O}$. The initial atomization temperature $\left(2700^{\circ} \mathrm{C}\right)$ was used for the pyrolysis curves according to the manual of the instrument. One hundred degree intervals were used for both pyrolysis and atomization temperature curves. For observing the thermal stability of lithium compound, we used temperatures from 500 to $1400^{\circ} \mathrm{C}$. The optimum atomization temperatures were determined by varying the temperature between 1800 and $2800^{\circ} \mathrm{C}$. The results are shown in Fig. 1A. Pyrolysis curves are
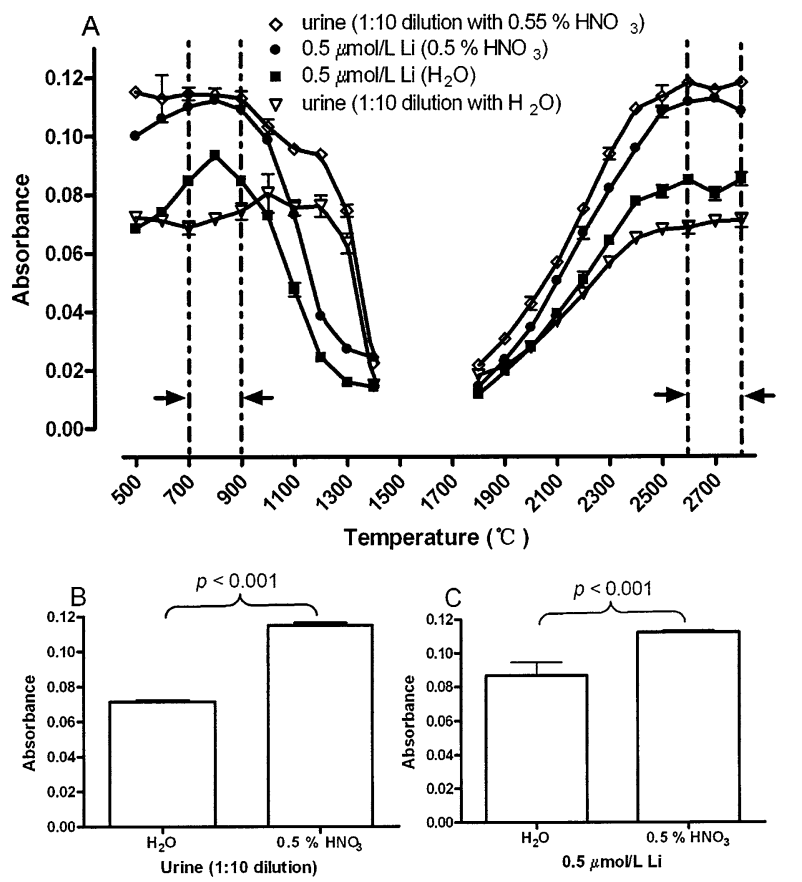

Fig. 1 Pyrolysis and atomization temperature curves of lithium in different kinds of media. $0.5 \mu \mathrm{mol} / \mathrm{L} \mathrm{Li}$ and natural urine (diluted 1:10) in either $\mathrm{H}_{2} \mathrm{O}$ or $0.5 \% \mathrm{HNO}_{3}$ solutions were determined by ETAAS. The atomization temperature was $2700^{\circ} \mathrm{C}$ for the pyrolysis curves and ash temperature was $800^{\circ} \mathrm{C}$ for the atomization curves. Panel A shows the pyrolysis and atomization temperature curves of lithium in different kinds of media. Arrows and dashed lines point out optimal temperatures for ash and atomization, respectively. Results are expressed as mean $\pm \mathrm{SD}$ of duplicate samples: filled symbol, $0.5 \mu \mathrm{mol} / \mathrm{L} \mathrm{Li}$; opened symbol, urine (diluted 1:10). Data of panels $\mathrm{B}$ and $\mathrm{C}$ were collected from panel $\mathrm{A}$ at the ash temperature of $800^{\circ} \mathrm{C}$ and atomization temperature of $2700^{\circ} \mathrm{C}$. Results are expressed as mean \pm SD of quadruplicate samples.

on the left part and atomization curves are on the right part. The optimal ash and atomization temperature ranges are pointed out by arrows and dashed lines. Eight hundreds and $2700^{\circ} \mathrm{C}$ were selected as the ash and atomization temperatures, respectively, according to the data from the pyrolysis and atomization temperature curves for determining urinary lithium in our experiments. We noticed that signals in $0.5 \% \mathrm{HNO}_{3}$ were much stronger than those in pure $\mathrm{H}_{2} \mathrm{O}$, especially for urine samples (Figs. 1B and 1C). This was because chlorine existing in urine interfered with $\mathrm{Li}$ signals, while this kind of interference was suppressed by $0.5 \% \mathrm{HNO}_{3} .{ }^{24}$ Besides $\mathrm{HNO}_{3}$ had some ability to enhance the sensitivity of $\mathrm{Li}$ as the absorbance of $\mathrm{H}_{2} \mathrm{O}$ and $0.5 \%$ $\mathrm{HNO}_{3}$ blanks were the same (data not shown). This was because $\mathrm{NO}_{3}{ }^{-}$increased the numbers of free $\mathrm{Li}$ atoms during the atomization step.

\section{Interference of chloride}

To observe the interference of chloride, we compared standard curves of $0,0.1,0.2,0.3,0.4,0.5 \mu \mathrm{mol} / \mathrm{L} \mathrm{Li}$ in $\mathrm{H}_{2} \mathrm{O}$ and urine (diluted 1:10) with and without $30 \mathrm{mmol} / \mathrm{L} \mathrm{NaCl}$ (Fig. 2A). The slopes of the standard curves with $30 \mathrm{mmol} / \mathrm{L} \mathrm{NaCl}$ were much lower than the related curves that were measured without adding extra $\mathrm{NaCl}$. Perhaps this was due to the vaporization of $\mathrm{LiCl}$ during the pyrolysis step. ${ }^{25}$ The slope of the Li standard curve with $30 \mathrm{mmol} / \mathrm{L} \mathrm{NaCl}$ was only 0.00536 ; this value was much lower than the slope of the $\mathrm{NaCl}$-free $\mathrm{Li}$ standard curve (0.238). In urine, there is a large amount of ammonium which will react 

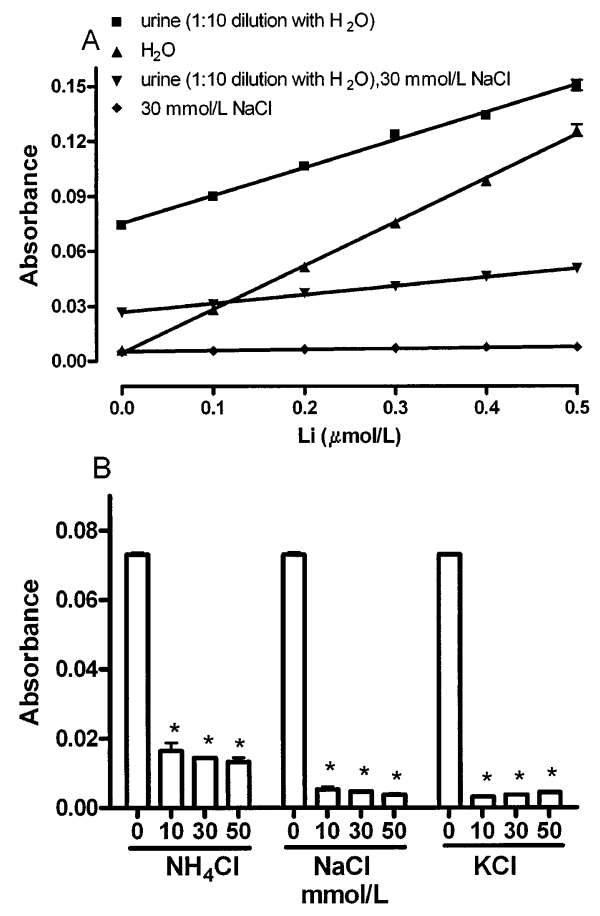

Fig. 2 Interference of chloride. Panel A shows the standard curves of $0,0.1,0.2,0.3,0.4,0.5 \mu \mathrm{mol} / \mathrm{L} \mathrm{Li}$ in $\mathrm{H}_{2} \mathrm{O}$ and urine (diluted $1: 10$ ) with or without $30 \mathrm{mmol} / \mathrm{L} \mathrm{NaCl}$. Panel B shows absorbance of 0.5 $\mu \mathrm{mol} / \mathrm{L} \mathrm{Li}$ in different kinds of chlorides. The ash and atomization temperatures used were 800 and $2700^{\circ} \mathrm{C}$, respectively. Results are expressed as mean $\pm \mathrm{SD}$ of duplicate samples. $*$ denotes $P<0.001$ in comparison with $0.5 \mu \mathrm{mol} / \mathrm{L} \mathrm{Li}$ in $\mathrm{H}_{2} \mathrm{O}$.

with chloride to produce ammonium chloride, which has low melting and boiling points. Thus, parts of ammonium chloride were vaporized and removed during the dry and ash steps and this reduced the interference of chloride.

To further validate that the interference was from chlorine, we used chlorides with different cations to test whether other chlorides could reduce the signal. Figure 2B shows the absorbance of $0.5 \mu \mathrm{mol} / \mathrm{L} \mathrm{Li}$ in different kinds of chlorides. The interference of $\mathrm{NH}_{4} \mathrm{Cl}$ was weaker, as compared with those of $\mathrm{NaCl}$ or $\mathrm{KCl}$. This is because parts of $\mathrm{NH}_{4} \mathrm{Cl}$ were vaporized during the ash stage as described above.

\section{Effects of different kinds of inorganic acids}

Chloride reacts with acids to produce hydrogen chloride, which has both a very low melting point and a very low boiling point. We compared the effect of eliminating the interference of chloride by different kinds of inorganic acids; $0.5 \mu \mathrm{mol} / \mathrm{L} \mathrm{Li}$ was used to evaluate the performance of $\mathrm{HNO}_{3}, \mathrm{H}_{2} \mathrm{SO}_{4}, \mathrm{H}_{3} \mathrm{PO}_{4}$ and $\mathrm{HCl}$ in the presence of $30 \mathrm{mmol} / \mathrm{L} \mathrm{NaCl}$ (Fig. 3). The amounts of hydrogen in all acid solutions were the same. All of the inorganic acids showed very good effects of eliminating the interference except $\mathrm{HCl}$; this exception further demonstrated that $\mathrm{Cl}^{-}$was the interferent.

\section{Superiority of nitric acid compared to ammonium nitrate}

$\mathrm{NH}_{4} \mathrm{NO}_{3}$ was considered a priority of the chemical modifier to eliminate the interference of chloride in the determination of trace lithium in biological samples. ${ }^{15,19,21-23}$ For comparing the discrepancy of the effect between $\mathrm{HNO}_{3}$ and $\mathrm{NH}_{4} \mathrm{NO}_{3}$, we used 10 - $120 \mathrm{mmol} / \mathrm{L} \mathrm{HNO}_{3}$ and $\mathrm{NH}_{4} \mathrm{NO}_{3}$ to determine the minimum effective dose in the presence of $0.5 \mu \mathrm{mol} / \mathrm{L} \mathrm{Li}$ and $30 \mathrm{mmol} / \mathrm{L}$

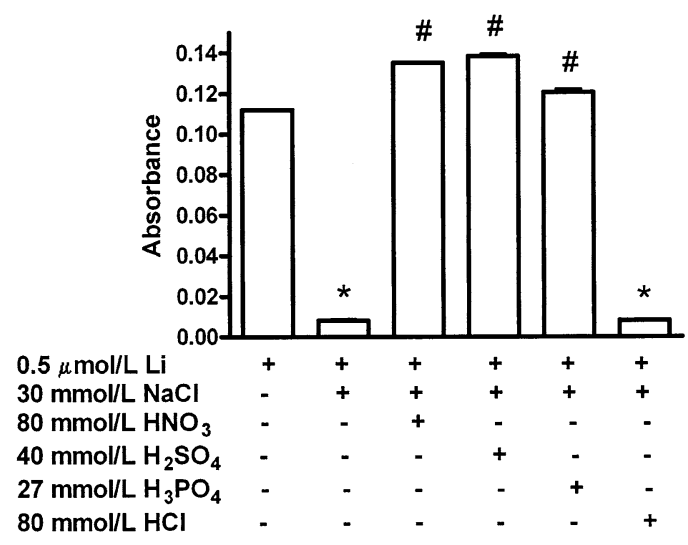

Fig. 3 Effect of inorganic acids. $\mathrm{HNO}_{3}, \mathrm{H}_{2} \mathrm{SO}_{4}, \mathrm{H}_{3} \mathrm{PO}_{4}$ and $\mathrm{HCl}$ were used to compare the effects of eliminating the interference of chloride. The amounts of hydrogen were equal $(80 \mathrm{mmol} / \mathrm{L})$ in different kinds of inorganic acid solutions. Results are expressed as mean \pm SD of duplicate samples. $*$ denotes $P<0.001$ in comparison with $0.5 \mu \mathrm{mol} / \mathrm{L} \mathrm{Li}$ in $\mathrm{H}_{2} \mathrm{O}$; \# denotes $P<0.001$ in comparison with $0.5 \mu \mathrm{mol} / \mathrm{L} \mathrm{Li}$ in $30 \mathrm{mmol} / \mathrm{L} \mathrm{NaCl}$.

$\mathrm{NaCl}$. Figure 4A shows the absorbance as functions of the concentrations of $\mathrm{HNO}_{3}$ and $\mathrm{NH}_{4} \mathrm{NO}_{3}$. As could be seen, each of them was effective, but $\mathrm{HNO}_{3}$ seemed to have a higher potency than $\mathrm{NH}_{4} \mathrm{NO}_{3}$. Both $60 \mathrm{mmol} / \mathrm{L} \mathrm{HNO}_{3}$ and $80 \mathrm{mmol} / \mathrm{L}$ $\mathrm{NH}_{4} \mathrm{NO}_{3}$ gave satisfactory absorbances. Then the absorbance reached to flat plateaus with the further increase of the concentration of either $\mathrm{HNO}_{3}$ or $\mathrm{NH}_{4} \mathrm{NO}_{3}$.

The effects of $\mathrm{HNO}_{3}$ and $\mathrm{NH}_{4} \mathrm{NO}_{3}$ were also checked by determining the $\mathrm{NaCl}$ background in the presence and absence of either of these reagents at the wavelength of $283.3 \mathrm{~nm}$ using a deuterium lamp. Testing samples were composed of $80 \mathrm{mmol} / \mathrm{L}$ $\mathrm{HNO}_{3}$ or $\mathrm{NH}_{4} \mathrm{NO}_{3}$ as chemical modifiers with 30,50 and 100 $\mathrm{mmol} / \mathrm{L} \mathrm{NaCl}$ as indicators of interferents. Background signals caused by $\mathrm{NaCl}$ were considerably completely eliminated (Fig. $4 \mathrm{Ba}$ ) or dramatically reduced (Figs. $4 \mathrm{Bb}$ and $4 \mathrm{Bc}$ ) in the presence of $80 \mathrm{mmol} / \mathrm{L} \mathrm{HNO}_{3}$. Figure 4B further demonstrated that $\mathrm{HNO}_{3}$ was more effective than $\mathrm{NH}_{4} \mathrm{NO}_{3}$ as a chemical modifier to eliminate the interference of chloride.

Variations of the slopes of lithium standard addition curves from various urine samples (10-fold dilution) were compared in the presence of either $80 \mathrm{mmol} / \mathrm{L} \mathrm{HNO}_{3}$ or $100 \mathrm{mmol} / \mathrm{L}$ $\mathrm{NH}_{4} \mathrm{NO}_{3}$. Results are shown in Table 2. Confidence interval analysis on the difference for the slopes of linear regression curves indicated significant differences between slopes of different standard addition curves in $100 \mathrm{mmol} / \mathrm{L} \mathrm{NH}_{4} \mathrm{NO}_{3}$ group $(P=0.013)$ with $\mathrm{CV}$ of $6.94 \%$; this value was not as high as reported by Magnin et al. ${ }^{15}$ since the dilution factors of the samples and concentrations of $\mathrm{NH}_{4} \mathrm{NO}_{3}$ were different. The $\mathrm{CV}$ value of $80 \mathrm{mmol} / \mathrm{L} \mathrm{HNO}_{3}$ group was $3.74 \%$ and $P=0.175$, which meant that the differences between slopes of different standard addition curves in this group were not significant.

Our experimental results proved Magnin's observation that the $\mathrm{CV}$ values of the slopes of lithium standard addition curves from various urine samples were high when using $\mathrm{NH}_{4} \mathrm{NO}_{3}$ as the chemical modifier. We would like to indicate that dilution is an easy and effective way to reduce interferents in samples. It would be much more effective to eliminate interferences when dilution was combined with chemical modifers.

The normal concentration of chlorine in urine is $170-250$ $\mathrm{mmol} / 24 \mathrm{~h}$ and the normal volume of urine is about $1.5 \mathrm{~L} / 24 \mathrm{~h}$. So the concentration of chlorine in urine is less than $200 \mathrm{mmol} / \mathrm{L}$. 

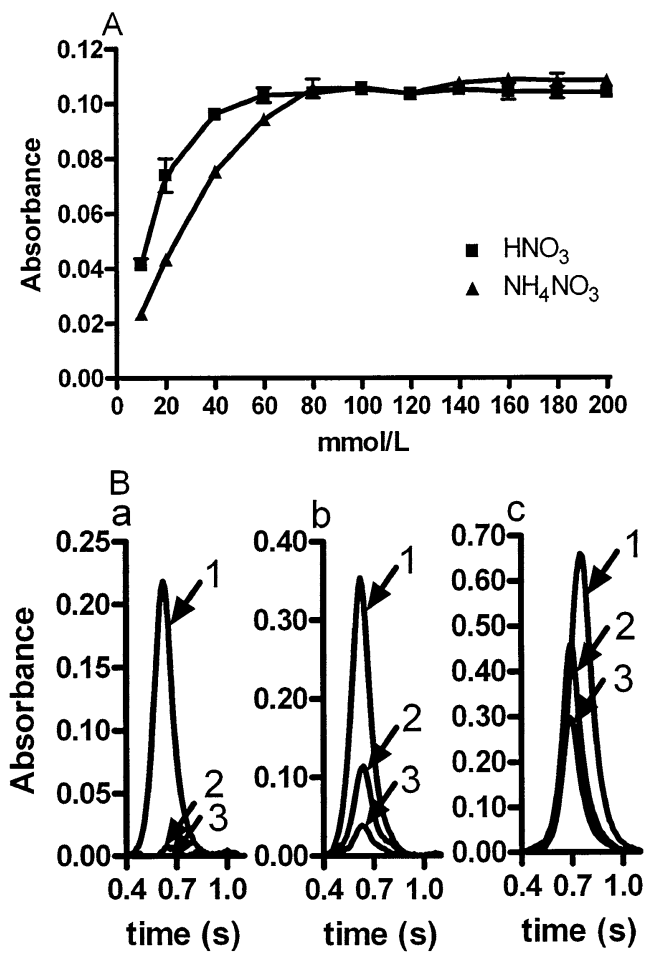

Fig. 4 Effect of nitric acid and ammonium nitrate. In panel A, $10-120 \mathrm{mmol} / \mathrm{L} \mathrm{HNO}_{3}$ and $\mathrm{NH}_{4} \mathrm{NO}_{3}$ were used to test the effect of eliminating the interference of chloride. $0.5 \mu \mathrm{mol} / \mathrm{L} \mathrm{Li}$ and 30 $\mathrm{mmol} / \mathrm{L} \mathrm{NaCl}$ were present in every specimen. Panel B shows the background signals due to $\mathrm{NaCl}$ in the absence and presence of $\mathrm{HNO}_{3}$ and $\mathrm{NH}_{4} \mathrm{NO}_{3}$. Concentrations of $\mathrm{NaCl}$ in Figs. $4 \mathrm{Ba}, 4 \mathrm{Bb}$ and $4 \mathrm{Bc}$ were 30,50 and $100 \mathrm{mmol} / \mathrm{L}$, respectively. Heating program of the graphite furnace was the same as that shown in Table 1. Background signals were measured by a deuterium lamp at the wavelength of $283.3 \mathrm{~nm}$. 1, $\mathrm{H}_{2} \mathrm{O} ; 2,80 \mathrm{mmol} / \mathrm{L} \mathrm{NH}_{4} \mathrm{NO}_{3} ; 3,80 \mathrm{mmol} / \mathrm{L} \mathrm{HNO}_{3}$ solutions.

By 10 times dilution in the process of sample preparation, the final concentration of chlorine in prepared samples should be less than $20 \mathrm{mmol} / \mathrm{L}$. As shown in Fig. $4 \mathrm{Ba}, 80 \mathrm{mmol} / \mathrm{L} \mathrm{HNO}_{3}$ has the ability to completely eliminate $30 \mathrm{mmol} / \mathrm{L}$ chlorine during dry and ash steps; this concentration of nitric acid should be available to eliminate the interference caused by chlorine in all urine samples.

\section{Slopes of lithium standard curves in $0.5 \% \mathrm{HNO}_{3}$}

The slopes of the standard curves were compared again. All of the conditions were the same as described in Fig. 2A except for containing $0.5 \% \mathrm{HNO}_{3}$ (Fig. 5). GraghPad Prism software was employed to test whether the slopes of the four standard curves were significantly different and the $P$ value was 0.146 . The differences were not significant. To further validate that the common standard curve could be used instead of using the standard addition, we tested the slopes of these two standard curves again; the result showed that the $P$ value was 0.123 . The differences between the slopes were not significant. This means that direct standardization with an aqueous calibration curve could be used for the determination of trace lithium in urine.

Possible mechanism of nitric acid as a chemical modifier and its advantages

The effectiveness of nitric acid in eliminating chloride interference results from the effect of this acid in releasing
Table 2 Slopes of urine-matched standard addition curves ${ }^{\mathrm{a}}$

\begin{tabular}{ccccccc}
\hline $\begin{array}{c}\text { Chemical } \\
\text { modifier }\end{array}$ & Mean & SD & $\begin{array}{c}\mathrm{CV}, \\
\%\end{array}$ & $n$ & $P$ & $\begin{array}{c}\text { Differences } \\
\text { between slopes }\end{array}$ \\
\hline $\begin{array}{c}80 \mathrm{mmol} / \mathrm{L} \\
\mathrm{HNO}_{3}\end{array}$ & 0.206 & 0.0077 & 3.74 & 7 & 0.175 & Not significant \\
$\begin{array}{c}100 \mathrm{mmol} / \mathrm{L} \\
\mathrm{NH}_{4} \mathrm{NO}_{3}\end{array}$ & 0.214 & 0.0148 & 6.92 & 7 & 0.013 & Significant \\
\hline
\end{tabular}

a. Addition of $0,0.1,0.2$ and $0.3 \mu \mathrm{mol} / \mathrm{L} \mathrm{Li}$ standards, respectively in each 10 -fold diluted urine sample.

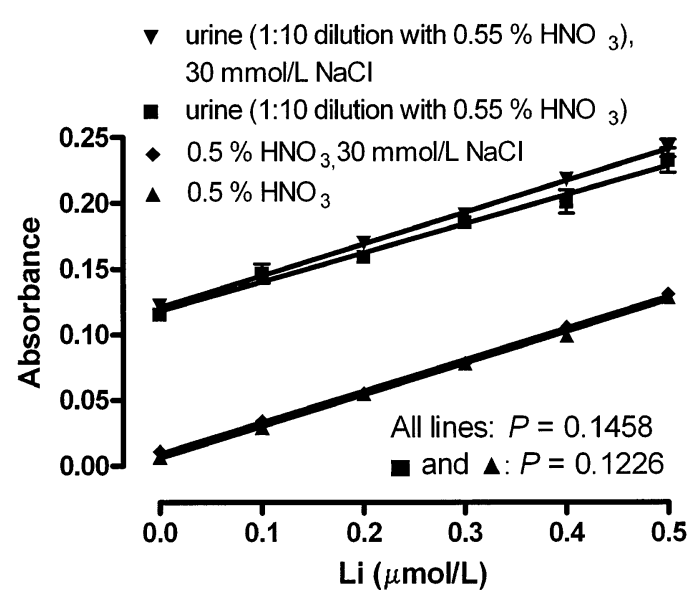

Fig. 5 Lithium standard curves in $0.5 \% \mathrm{HNO}_{3}$. Lithium standards were prepared in aqueous solutions and urine (diluted 1:10) with or without $30 \mathrm{mmol} / \mathrm{L} \mathrm{NaCl}$. All solutions contained $0.5 \% \mathrm{HNO}_{3}$. GraghPad Prism software was used to test whether slopes of linear regression curves were significantly different.

chloride as hydrogen chloride $(\mathrm{HCl})$ from the hot atmosphere. The procedure could be chemically expressed as follows:

$$
\mathrm{HNO}_{3}+\mathrm{MCl} \longrightarrow \mathrm{MNO}_{3}+\mathrm{HCl},
$$

\section{M represents metal.}

Nitric acid reacts with chloride to form nitrate and volatile hydrogen chloride, which has a very low melting point $\left(-114.8^{\circ} \mathrm{C}\right)$ and boiling point $\left(-85^{\circ} \mathrm{C}\right)$. The dried hydrogen chloride is very stable and volatilized from the hot atmosphere during the dry step of ETAAS.

Normally $0.5 \% \mathrm{HNO}_{3}$ is widely recommended as a medium for different elements determination by atomic absorption spectrometry. So no extra specific chemical modifiers are needed if $0.5 \% \mathrm{HNO}_{3}$ existed while determining trace lithium in urine by ETAAS.

\section{Application}

The developed method was applied to the determination of trace lithium in human urine. Seventy-five samples (including 47 from males and 28 from females) were measured. The minimum, maximum, mean \pm SD were $1.38,21.4,6.69 \pm 3.74$ $\mu \mathrm{mol} / 24 \mathrm{~h}$ urine for males and $1.57,16.2,5.99 \pm 3.18 \mu \mathrm{mol} / 24 \mathrm{~h}$ urine for females. $t$-test was applied to examine whether the results between males and females differed significantly at the 95\% confidence level limit. There was no statistically significant difference $(P=0.414)$. 


\section{Acknowledgements}

This work was supported in part by research grants by the Chinese National Natural Science Foundation (30771184) and the National Key Program (973) for Basic Research of China (2004CB518600).

\section{References}

1. P. A. Boer, J. M. Morelli, J. F. Figueiredo, and J. A. Gontijo, Life Sci., 2005, 76, 1805.

2. P. P. Leyssac and P. Christensen, Acta Physiol. Scand., 1994, 151, 173.

3. I. Dol, M. Knochen, and E. Vieras, Analyst, 1992, 117, 1373.

4. F. Bianchi, M. Maffini, A. Mangia, E. Marengo, and C. Mucchino, J. Pharm. Biomed. Anal., 2007, 43, 659.

5. K. Iguchi, K. Usuda, K. Kono, T. Dote, H. Nishiura, M. Shimahara, and Y. Tanaka, J. Anal. Toxicol., 1999, 23, 17.

6. P. Leflon, R. Plaquet, F. Rose, G. Hennon, and N. Ledeme, Anal. Chim. Acta, 1996, 327, 301.

7. P. Heitland and H. D. Köster, Clin. Chim. Acta, 2006, 365, 310.

8. B. Bocca, G. Forte, F. Petrucci, O. Senofonte, N. Violante, and A. Alimonti, Ann. Ist. Super. Sanita, 2005, 41, 165.

9. N. M. de Roos, J. H. de Vries, and M. B. Katan, Am. J. Clin. Nutr., 2001, 73, 75.

10. D. G. Fleishman, S. P. Gambaryan, E. A. Lavrora, V. A. Nikiforov, A. A. Saulus, and V. F. Vasilieva, C. R. Acad. Sci. III, 1990, 311, 37.
11. H. R. Schulten, R. Palavinskas, and K. Kriesten, Biomed. Mass Spectrom., 1983, 10, 192.

12. J. Seidlerová, J. A. Staessen, M. Maillard, T. Nawrot, H. Zhang, M. Bochud, T. Kuznetsova, T. Richart, L. M. Van Bortel, H. A. Struijker-Boudier, P. Manunta, M. Burnier, R. Fagard, and J. Filipovský, Hypertension, 2006, 48, 609.

13. A. Chiolero, M. Maillard, J. Nussberger, H. R. Brunner, and M. Burnier, Hypertension, 2000, 36, 631.

14. J. Zhou and X. Sun, Spectrosc. Spect. Anal., 1999, 19, 604.

15. J. L. Magnin, L. A. Decosterd, C. Centeno, M. Burnier, J. Diezi, and J. Biollaz, Pharm. Acta Helv., 1996, 71, 237.

16. P. P. Leyssac and P. Christensen, Acta Physiol. Scand., 1996, 156, 131.

17. P. Boer, R. Fransen, W. H. Boer, and H. A. Koomans, Am. J. Physiol., 1995, 268, F1229.

18. M. Shalmi, J. D. Kibble, J. P. Day, P. Christensen, and J. C. Atherton, Am. J. Physiol., 1994, 267, F695.

19. F. Steinhäuslin, M. Burnier, J. L. Magnin, A. Munafo, T. Buclin, J. Diezi, and J. Biollaz, J. Am. Soc. Nephrol., 1994, 4, 1429 .

20. B. Peter, F. René, H. B. Walther, and A. K. Hein, J. Anal. At. Spectrom., 1993, 8, 611.

21. N. L. Miller, J. A. Durr, and A. C. Alfrey, Anal. Biochem., 1989, 182, 245

22. S. Luan, X. Shan, and Z. Ni, J. Anal. At. Spectrom., 1988, 3, 989.

23. G. A. Trapp, Anal. Biochem., 1985, 148, 127.

24. D. J. Churella and T. R. Copeland, Anal. Chem., 1978, 50, 309.

25. K. Dash, S. Thangavel, S. C. Chaurasia, and J. Arunachalam, Anal. Chim. Acta, 2007, 584, 210. 